УДК 324

\title{
К ВОПРОСУ ОБЩЕЙ ХАРАКТЕРИСТИКИ ЭЛЕКТОРАЛЬНЫХ ТЕХНОЛОГИЙ
}

\author{
Бурдейный Владислав Владимирович \\ кандидат философских наук, научный сотудник \\ Западный филиал РАНХиГС
}

\begin{abstract}
Аннотация: Целью работы является анализ разновидностей, выявление особенностей формирования и применения электоральных технологий. Исследовательский интерес сосредоточен на вопросах специфики влияния этих технологий на общественное сознание во время избирательных кампаний.

Ключевые слова: политические технологии, электоральные технологии, выборы, выборная кампания, политический менеджер.

\section{ON THE QUESTION OF THE GENERAL CHARACTERISTICS OF ELECTORAL TECHNOLOGIES}

\section{Burdeyny Vladislav Vladimirovich}

\begin{abstract}
The purpose of the work is to analyze the varieties, identify the features of the formation and application of electoral technologies. Research interest is focused on the specifics of the impact of these technologies on public consciousness during electoral campaigns.

Key words: political technologies, electoral technologies, elections, election campaign, political manager.

Электоральные технологии являются разновидностью политических технологий. Термин «технология» происходит от древнегреческого

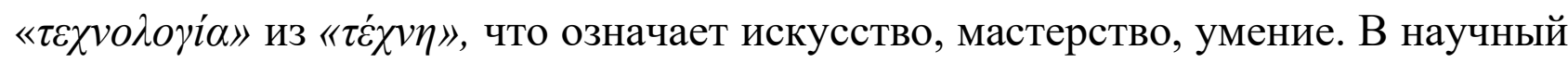
же оборот понятие «технология» было введено немецким ученым И. Бекманом (1739-1811 гг.). Этим понятием он назвал научную дисциплину, читавшуюся им в германском университете в Геттинге с 1772 г.
\end{abstract}




\section{СОВРЕМЕННЫЕ СОЦИАЛЬНО-ЭКОНОМИЧЕСКИЕ ПРОЦЕССЫ: ПРОБЛЕМЫ, ТЕНДЕНЦИИ, ПЕРСПЕКТИВЫ}

Российский политолог А.И. Соловьев считает, что политические технологии представляют собой совокупность последовательно применяемых процедур, приемов и способов деятельности, направленных на наиболее оптимальную и эффективную реализацию целей и задач конкретного субъекта в определенное время и в определенном месте [1]. Согласимся с мнением исследователя, уточнив, что под политическими технологиями можно понимать действия, повышающие эффективность политических групп, организаций, их лидеров, а также государств, участвующих в борьбе за политическое доминирование. Но здесь необходимо учитывать, что электоральные процессы ограничены во времени рамками избирательных кампаний. Поэтому электоральные технологии можно рассматривать как особую разновидность политических технологий, используемых в ходе избирательных кампаний.

Электоральные технологии по содержанию и форм реализации можно разделить на стратегические и тактические. Стратегические электоральные технологии включают структурные и целевые методы, а также специальные политические проекты.

Структурные методы предполагают создание избирательных штабов и разработку плана политической кампании. В основе эффективной штабной структуры лежит универсальная функционально-проектная схема, модифицированная под конкретную политическую кампанию. Политический штаб определяет стратегическое направление всей кампании.

К стратегическим электоральным технологиям также можно причислить и специальные проекты. Под политическим проектом можно понимать специфическую политтехнологическую работу, которая начинается задолго до избирательной кампании и может быть замаскирована под неполитические формы деятельности. Политические проекты могут использоваться политическими партиями совместно с общественными организациями, бизнесом и ассоциациями граждан; политической властью для переизбрания на разных уровнях - от центрального до регионального и местного самоуправления.

В структуре тактических электоральных технологий обычно выделяют аналитические, медийные и полевые методы [2].

Аналитическая диагностика предназначена не только для оценки текущей эффективности проведения политической кампании, но и для того, чтобы помочь скорректировать тактический эскиз кампании. В это время проводятся 
количественные замеры электоральных рейтингов партий или кандидатов. То же самое осуществляется и по отношению к конкурентным политическим силам. Также проводятся качественные измерения. Так, SWOT-анализ имиджа оппонента, методы фокус-групп, глубинные и экспертные интервью успешно сочетаются с политическими и маркетинговыми исследованиями. С помощью тех же качественных исследований тестируются агитационно-пропагандистские материалы, рассчитанные на целевую аудиторию.

Кроме того, аналитическое направление политтехнологической работы предполагает мониторинг СМИ. При этом учитываются целевые аудитории СМИ. К примеру, периодические печатные издания можно разделить на деловую и общественно значимую прессу. В зависимости от поставленных задач прессу можно разделить на «желтую», «научно-популярную», «гламурную» и т.п. Аналогичный мониторинг проводится в отношении целевых сегментов Интернета, телевидения и радио.

Аналитические процедуры, путем изучения агитационно-пропагандистских материалов оппонентов, размещаемых ими в СМИ, позволяют с высокой степенью точности определить их целевые группы и даже концепцию имиджа конкурентов. Наблюдая за действиями оппонентов, можно, к примеру, составить целый видеоряд из их оговорок, ошибок, курьезных противоречий, неудачных фраз, мимики и жестикуляции, а затем транслировать его по телевидению и в Интернете. Это способ позволяет проанализировать весь массив выступлений конкурента и, обнаружив сомнительные высказывания, выстроить блок компрометирующих вопросов на теледебатах, которые могут завести в тупик или вывести оппонента из равновесия. Оговорки оппонентов также могут быть использованы в открытых письмах «возмущенных читателей» в редакции газет. Кроме того, собранная компрометирующая информация часто может быть востребована юристами для судебных разбирательств.

Для формирования у респондентов определенного отношения к участникам политической кампании также практикуются «направляющие» опросы. Примерами вопросов их таких «направляющих» опросов могут быть следующие: «Как вы относитесь к криминальному прошлому депутата X?», «Как вы относитесь к тому факту, что спонсором политической партии Y являлся г-н Z?» и т.п. Параллельно в печати и в Интернете могут появиться 


\section{СОВРЕМЕННЫЕ СОЦИАЛЬНО-ЭКОНОМИЧЕСКИЕ ПРОЦЕССЫ: ПРОБЛЕМЫ, ТЕНДЕНЦИИ, ПЕРСПЕКТИВЫ}

заказные статьи, предлагающие политические прогнозы от имени определенных политологов, экспертов и аналитиков, которые окажут манипулятивное воздействие на общественное мнение.

Конкуренты могут использовать те же технологии с целью создания негативного образа конкретного политического лидера или партии в целом. Существуют несколько эффективных методов борьбы с этими агрессивными устремлениями. Например, технология «вакцинации» целевых групп заключается в упреждающем создании такой ситуации, при которой компрометирующие материалы, опубликованные оппонентами, не будут восприняты целевой аудиторией всерьез. В таких случаях заблаговременно публикуются «аналитические статьи» о возможной информационной диверсии со стороны экстремистов. Эффект достигается с помощью перепечатки материала в газетах. Технология «доведения до абсурда» означает предъявление обвинения самому себе через подставные каналы, якобы от политических оппонентов, абсурдность которого понятна любому здравомыслящему человеку. С помощью технологии «перефокусировки внимания» создаются яркие информационные поводы, фейк-новости, отвлекающие внимание от основного события.

Российский исследователь электоральных технологий В.В. Полуэктов выделяет так называемые полевые методики, которые являются наиболее активной частью работы политического менеджера [3]. К ним относятся, прежде всего, кампании «от двери до двери», в рамках которых проводится поквартирный обход населения с помощью агитаторов. В них участвуют те, кого жители знают или кому доверяют в среде определенной целевой группы студенты, школьные учителя, врачи, почтальоны.

В настоящее время стали популярны так называемые soft-meхнологии, которые предназначены для косвенного формирования электоральных предпочтений. В данном случае широко используется «сбор наказов» избирателей. Сначала создается информационный повод, суть которого в том, что кандидат приступил к разработке будущих реформ на основе наказов народа. Затем организуется масштабный сбор этих наказов через сеть общественных приемных, одновременно создается адресная база данных жителей. После этого разрабатывается программа действий, и путем директ-технологий рассылаются именные благодарности жителям, давших наказы. 
Сильное влияние на электоральный процесс оказывает использование властью административного ресурса, как в пользу поддерживаемого им кандидата, так и против конкурентов. Это арсенал очень богат и разнообразен. Примеры таких технологий приводит российский исследователь А.Ю. Бузин [4, с. 237]. В частности он выделяет, что технологию «карусели», которая означает организованное массовое голосование на нескольких избирательных участках по подложным бюллетеням или открепительным удостоверениям; технологию давления на кандидатов путем запугивания их правоохранительными органами и всевозможными административными проверками. Власти широко используют метод «стерилизации» избирательного бюллетеня, предполагающий недопущение к выборам нежелательных кандидатов и избирательных объединений. Поводом для отказа в регистрации может быть неправильное оформление или неполнота документов, представленных для регистрации. Практикующейся технологией является обеспечение явки и принуждение к голосованию через учреждения образования, здравоохранения, культуры, социальных и административных служб, правоохранительные органы и армию.

Таким образом, отметим, что электоральные технологии в современном мире разнообразны и определяют исход голосования. Успех их применения зависит от уровня мастерства политического менеджера и финансовых возможностей кандидатов. В то же время политические менеджеры не должны забывать о морально-этической стороне проблемы и личной ответственности при формировании выборных органов власти.

\section{Список литературы}

1. Соловьев А.И. Политология. Политическая теория. Политические технологии. - М.: Аспект Пресс, - 2006 [Электронный ресурс]. Режим доступа: http://yanko.lib.ru/books/politologiya/politology-solovyev-2006-a.htm.

2. Володенков С.В. Управление современными политическими кампаниями. - М.: Изд-во Московского университета, - 2012 [Электронный pecypc]. Режим доступа: https://fb2lib.ru/volodenkov-s-v/upravlenie-sovremennymi -politicheskimi-kampaniyami/.

3. Полуэктов В.В. От двери к двери: Полевые технологии в избирательных кампаниях. - М.: Русская панорама, - 2002 [Электронный pecypc]. Режим доступа: http://wciom.ru/index.php?id=459\&uid=1 14301 .

4. Бузин А.Ю. Административные избирательные технологии и борьба с ними. - М.: Центр «Панорама», - 2007. - 271 с. 